\title{
Investigations on mass transfer mechanism in the course of laser-assisted alloying of corrosion-resistant stainless steels with silicon and carbon
}

\author{
T. V. Tarasova \\ Bauman Moscow State Technical University \\ ttv@,bmstu.ru
}

The methods to modify product's surface via changing chemical composition in the surface layers have a good practical record, as they allow to increase the durability and to reduce the material costs. The laser alloying is a special method of such surface modification, in which the introduction of alloying elements into the melt bath occurs at high speeds of heating and cooling, thus making possible to stabilize non-equilibrium concentration structures and, on their basis, to get new phase compositions [1-3]. Theoretical and experimental studies so far done show that, in case of the laser treatment of alloy surface and after the hardening of the melted area, a redistribution of alloying elements takes place over the whole melted area. The mechanism of such mass transfer is quite complicated and has found so far no uniform interpretation. Some works show that the transfer process is based on a circulation movement, and the mobility of the melt is due to the thermo capillary effect. On the melt surface, the temperature is decreasing from the center of irradiation towards the borders of the liquid bath. As the temperature varies, the surface tension is changing with it, increasing towards the liquid bath periphery; consequently the melt sets into motion from the center outwards. This surface movement is transmitted into the depth by force of the friction. In [4], an approximate calculation has been done of the melt movement and of the variations of the melt's surface. The calculation done for iron (the width and depth of the melting zone being $2 \mathrm{~mm}$ and $0.2 \mathrm{~mm}$, correspondingly; the temperature difference at the center and at the boundary $500{ }^{\circ} \mathrm{C}$ ) showed that in the surface layer the melt mass can attain the speed of $1-3 \mathrm{~m} / \mathrm{sec}$, and in deeper regions - up to some tens of $\mathrm{cm} / \mathrm{sec}$. The model based on the thermo capillary effect is capable to explain high observed speeds of the mass transfer and the melt's mixing.

The aim of the present contribution is a study of the mass transfer mechanism in martensitic stainless and corrosion-resisting steels (12X13, 20X13, 40X13). The samples were treated with the "Quantum-16" laser under regimes guaranteeing the surface melting. Preliminarily the surface was covered with the plaster of graphite and silicon powders, with an organic binding component. The samples were treated after the laser having reached the stable operation mode. The power density was varied by changing either the pulse energy or the sample position with respect to the focal plane of the laser exit lens. Depending on the power density and the plaster thickness, different structures of the strengthened zone have been obtained, so that the zone had different characteristic distributions of the micro hardness along the cross-section of the melt bath. The micro hardness was measured by the PMT-3 device, with the load onto the indenter being $0.98 \mathrm{~N}$. The structure and the phase composition of the melting zones were further on investigated by the X-ray analysis, light and electronic microscopy [5]. The distribution of iron, chromium and silicon was investigated by a well established method [5], using an X-ray microanalyzer "MS-46" of Cameca. The images of thin cuts were studied in absorbed and secondary electrons, as well as in the characteristic radiation.

For the study of carbon distribution, the activation autoradiogram method was used. The investigated materials were irradiated by deuterons of $1.8 \mathrm{MeW}$ energy for 15 minutes. In the process, the radionuclide ${ }^{13} \mathrm{~N}$, formed in thin surface layer along the ${ }^{12} \mathrm{C}(\mathrm{d}, \mathrm{n}){ }^{13} \mathrm{~N}$ reaction, 
exhibited the local activity strictly proportional to the carbon concentration in the investigated material. The distribution ${ }^{13} \mathrm{~N}$ over the irradiated surface was registered with a photo film used for nuclear research. The resulting autoradiograms were developed with metolhydroquinone developer D-19 that provides the linear dependence between the irradiation dose and the nigrescence density of autoradiogram. The obtained autoradiogram was then photo metered on the MF-4 device, whose logarithmic amplifier provided linear dependence of the output signal on the nigrescence density of the autoradiogram and, consequently, on the carbon concentration, which can be measured by this method with the accuracy of $10^{-3} \%$.

For the study of the silicon distribution, the samples were irradiated with deuterons from silicon, along the ${ }^{30} \mathrm{Si}(\mathrm{d}, \mathrm{p}){ }^{31} \mathrm{Si}$ reaction. At this, the ${ }^{31} \mathrm{Si}$ radionuclide was formed. The sensitivity of measuring the silicon concentration is about $10^{-2} \%$. Due to a large difference in the half-lives of ${ }^{13} \mathrm{~N}$ and ${ }^{31} \mathrm{Si}$ nuclides, their mutual spoiling of respective autoradiograph analyses can be easily minimized, so that unambiguous pictures of $\mathrm{C}$ and $\mathrm{Si}$ distribution in the same sample could be obtained.

Results and discussion. The investigations have shown that the structure and the micro hardness under the laser alloying are changing only in the melt zone and close to the border between the melt zone and the thermo influence zone. Examining the cuts obtained after a single laser action, one can observe light and dark stains - the areas enriched or depleted with alloying elements. There is an abrupt change of the micro hardness between these areas. The shape of the stains testifies to existence of turbulent flows as the melt zone were in liquid state. The type of these flows determines the distribution of matter over the whole liquid region, under the influence of the forces acting in the melt (figures 1 and 2).

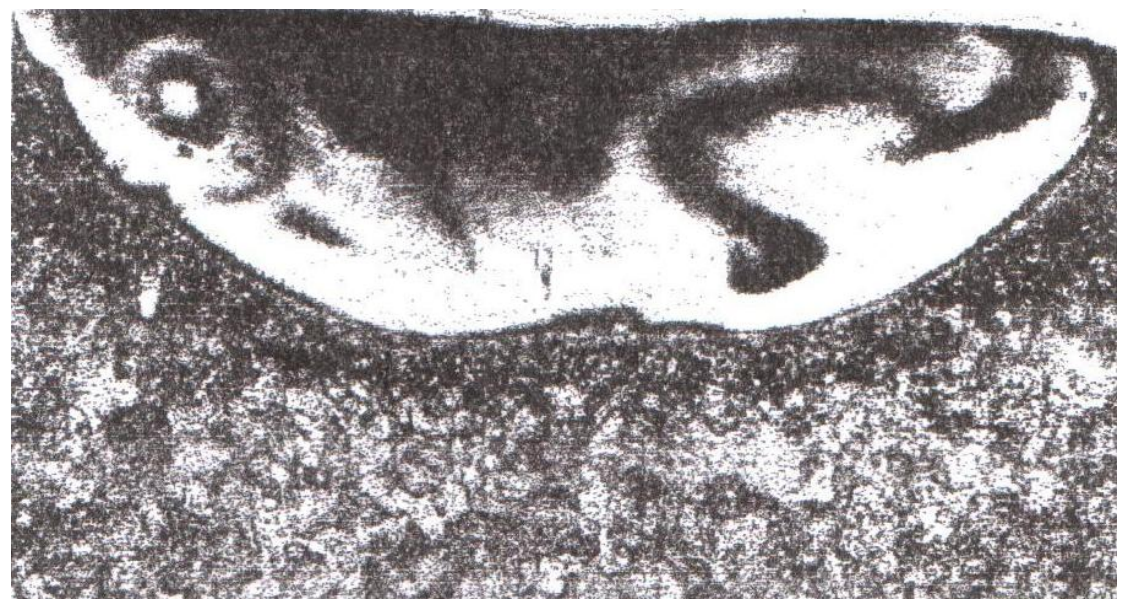

Figure 1: Microstructure of the melt zone. $12 \mathrm{X} 13$ steel under laser cementation $(\mathrm{E}=15$ watt-second, $\delta=0.4 \mathrm{~mm}, \Delta \mathrm{F}=0$ )

In order to estimate the element distribution after laser-assisted siliconizing, the curves of $\mathrm{Cr}$, Fe and $\mathrm{Si} K_{\alpha 1,2}$ intensity along some directions (figure 3) were registered. The measurement showed that, upon small (up to 1\%) enrichment of the melt bath with silicon, the variation amplitude of the silicon intensity curve increased sharply at the edges (figure 3 ), on the surface and at the bottom of the melt bath. Moreover when scanning along the direct line transversing the center of the bath from the surface into the bottom, an increase of silicon concentration was noted in the center of the melt bath. At that the micro hardness was $7500 \mathrm{MPa}$ in the area with higher silicon concentration and $5500 \mathrm{MPa}$ - with reduced silicon concentration. Similar changes were detected under other alloying regimes which yielded higher silicon concentration (up to $3.5 \%$ ) in the strengthened areas, but the difference 
between the variation amplitudes of the curve silicon intensity at edges of the melt bath was less pronounced. The detected curves of the $\mathrm{Fe}$ and $\mathrm{Cr} K_{\alpha 1,2}$ intensity exhibit a smoothening of the micro-inhomogeneities of composition, as compared to the initial state.

Figure 2:

Microstructure of the melt zone. 12 X13 steel under laser siliconizing $(\mathrm{E}=15$ watt-second, $\delta=0.1 \mathrm{~mm}, \Delta \mathrm{F}=0)$.

The scanning direction of micro analyzer along the sample surface is shown by arrow marked "I".

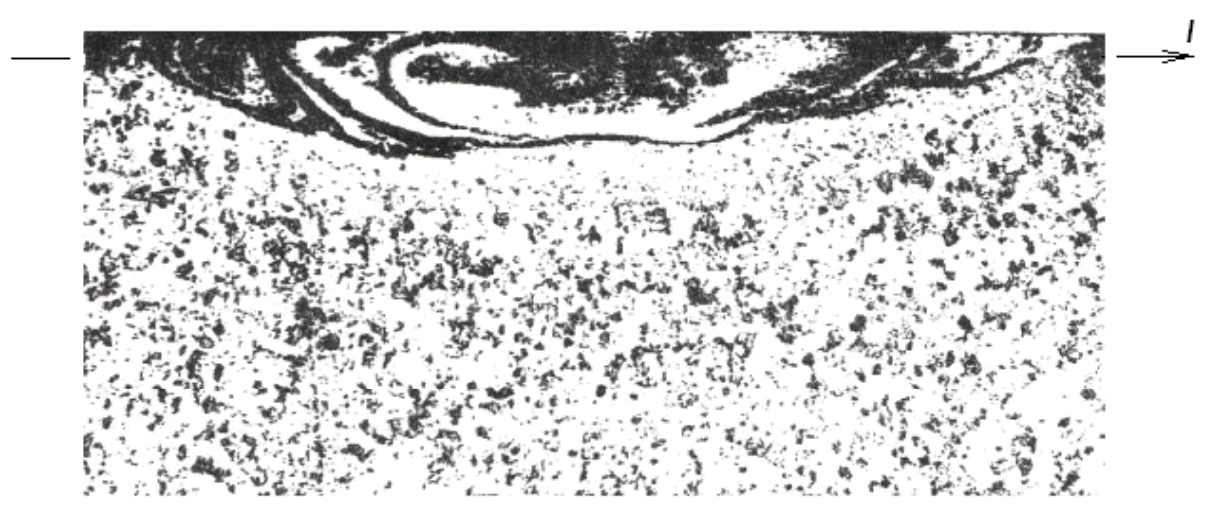

The treatment with a double laser impulse resulted in a smoothening of the silicon concentration over the volume of the melt zone. An increase (up to 20\%) of the silicon concentration in the strengthened zone resulted in the damping of intensity variation, so that the fluctuations were roughly of the same order over the whole volume of the melt bath. The distribution of the micro-hardness also became more uniform, with the maximal microhardness of about $10000 \mathrm{MPa}$, and the local scattering of its values negligible, within the measurement error. An alloying with an overlap of strengthened zones resulted in even better balanced distribution of elements in the siliconized layer. The analysis of the elements' distribution under the laser-assisted alloying with burn-off allows to assume that the mass transfer occurs due to the thermo capillary effects, consistently with the results of [4].

The distribution of elements was also analyzed under the laser-assisted cementation. Comparing the micro structures of laser strengthening zones (which were formed during laser cementation) with the autoradiograms (which provide information about the local carbon distribution) showed that, at low average carbon concentration, the typical whirlwinds are shown in the photos of the microstructure, and nigrescence corresponding to them - in the autoradiogram. The laser treatment by a double impulse resulted in a leveling of the carbon concentration over the volume of the melting bath. The contrast over nigrescence densities in the autoradiogram decreased as the carbon content increased (figure 4). On analyzing the autoradiogram and the photos of microstructure of strengthened zones one can see that the carbon concentration is decreasing near the edges of the melt zone. It happens because the intensity of mix process is less efficient in these areas, owing to lower reheat temperature and shorter time of the melt staying in liquid and viscous state. The study of the $\mathrm{Fe}$ and $\mathrm{Cr}$ distribution by the X-ray spectral microanalysis showed that the distribution of these elements is more uniform, as comparing to pre-treated metal. The comparison of the X-ray spectrum microanalysis data with those from metallographic analysis and X-ray structure analysis confirm an absence of special chromium carbides. Hence we can suppose that chromium enters fine-dispersed carbides like $(\mathrm{Fe}, \mathrm{Cr})_{3} \mathrm{C}$ and is equally distributed over structural components, i.e., the martensite, austenite and carbides contain equal quantity of chrome. The observed homogeneity of composition after laser alloying can be explained by intense melt circulation and melt mixing under the influence of the mechanisms described above. 


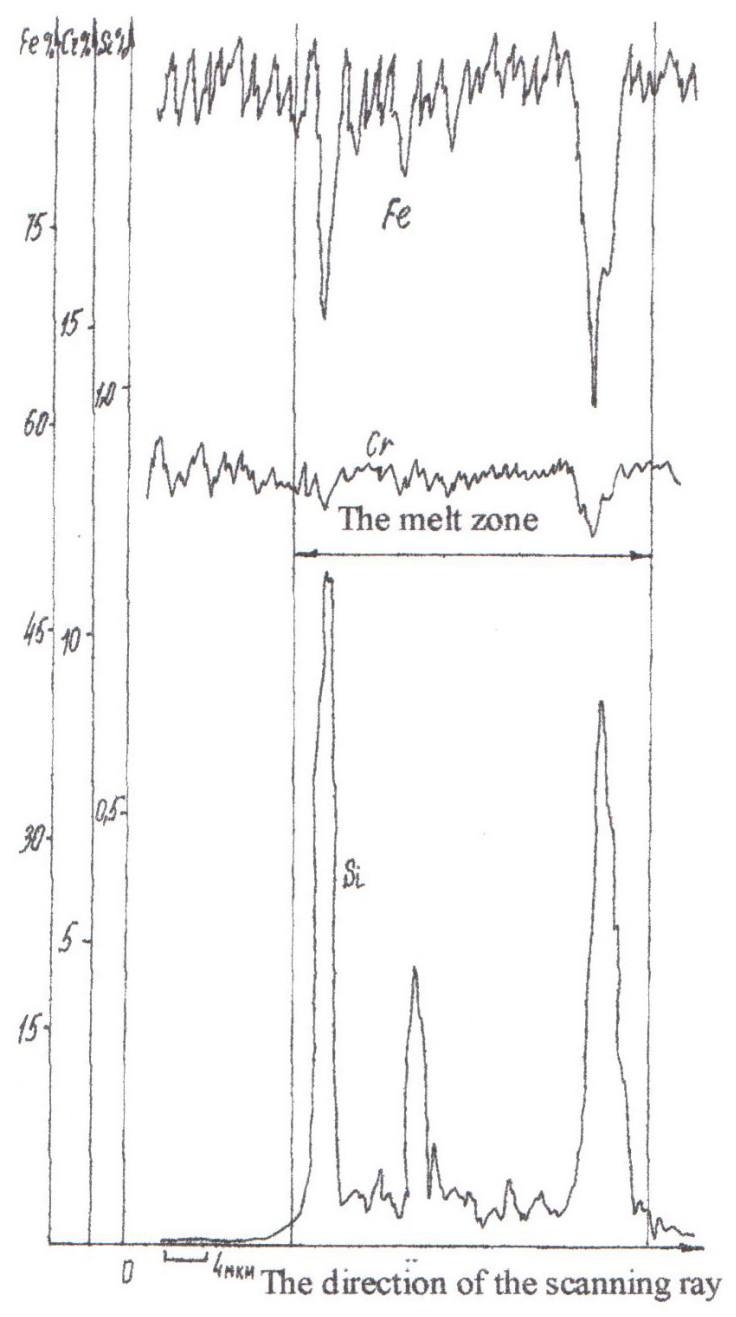

Figure 3: The iron, chromium and silicon distribution profiles after laser cementation in the $12 \mathrm{X} 13$ steel $(\mathrm{E}=15$ watt-second, $\delta=0.4 \mathrm{~mm}, \Delta \mathrm{F}=0)$

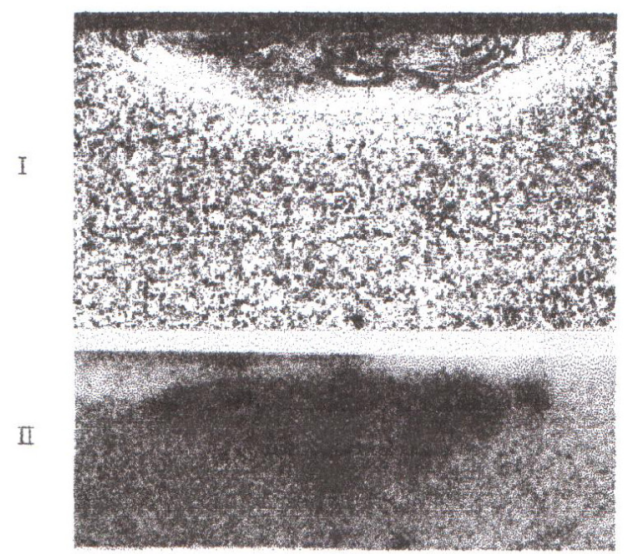

Direction of the photometry

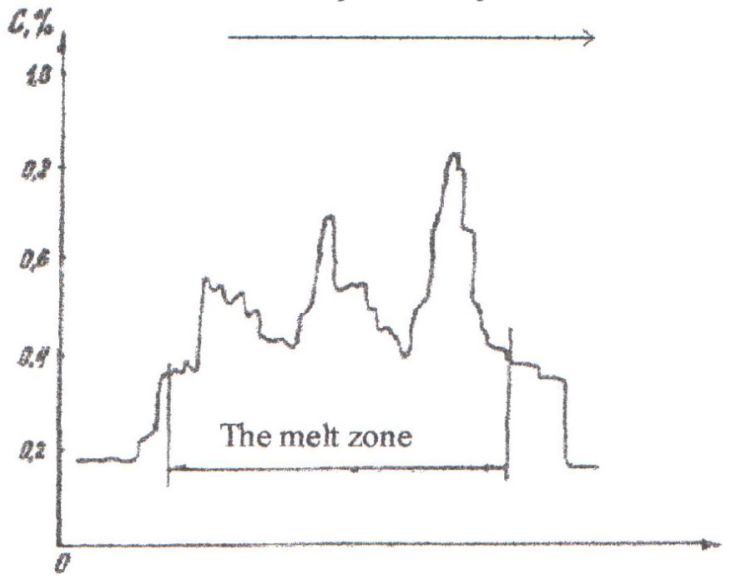

Figure 4: The carbon distribution profile after laser cementation in the $12 \mathrm{X} 13$ steel ( $\mathrm{E}=15$ watt-second, $\delta=0.4 \mathrm{~mm}, \Delta \mathrm{F}=0$ )

Summarizing, the analysis of the mass transfer under the laser alloying of martensitic stainless and corrosion-resisting steels by nonmetallic components (carbon and silicon) showed that the movements in the melt are primarily due to the thermo capillary effect.

1. T.V. Tarasova, M.L. Larin, V.M. Minaev, Investigation of the laser alloying of corrosion-resistant chromium steels (in Russian). In: Laser thermic and chemical-thermic treatment in mechanical engineering. The MADI Edition (Moscow, 1985), p. 48-53.

2. Yu.M. Lakhtin, Ya.D. Kogan and T.V. Tarasova, Investigation of the processes of laser-assisted alloying of corrosion-resistant alloys (in Russian). Electronnaya obrabotka materialov No.3, p. 28-31 (1985).

3. A.N. Safonov and T.V. Tarasova, The processes of laser alloying of stainless steels by nonmetallic components (in Russian). Vestnik MGTU, Ser. "Mashinostroenie", No.2, p. 68-77 (1997).

4. I.P. Borovsky, D.D. Gorodsky, I.M. Sharafeev et al. The mass transfer during the burning-off treatment of metal surfaces by continuous laser radiation (in Russian). Doklady Akademii Nauk SSSR 263, No.3, p.616-618 (1982).

5. S.S. Gorelik, Yu.A. Skakov and L.N. Rastorguev. The X-ray and electron-optical analysis. A textbook for high school. Third edition (in Russian). The MISIS Edition (Moscow, 1994), 328 pp. 